\title{
Impact of cardiovascular risk factors on coronary heart disease and mortality among middle aged diabetic men: a general population study
}

\author{
Annika Rosengren, Lennart Welin, Alecka Tsipogianni, Lars Wilhelmsen
}

\begin{abstract}
Objective-To investigate the effect of cardiovascular risk factors on coronary heart disease and all cause mortality in middle aged diabetic men.

Design-Prospective population study based on data collected from second screening (from 1974 to 1977) in the multifactor primary prevention trial and follow up until March 1983.

Setting-Gothenburg, Sweden.

Subjects-6897 Men aged 51 to 59 , of whom 232 were self reported diabetics and 6665 were non-diabetic; none had a history of myocardial infarction.
\end{abstract}

Main outcome measures-Incidences of coronary heart disease and mortality from all causes.

Results-Diabetic men with a serum cholesterol concentration $>7.3 \mathrm{mmol} / 1$ had a significantly higher incidence of coronary heart disease during follow up than those with a concentration $\leqslant 5.5 \mathrm{mmol} / \mathrm{l}$ (28.3\% $v 5.4 \% ; p=0 \cdot 020)$; corresponding figures for non-diabetic men were $9.4 \%$ and $2.4 \%$ respectively. In multivariate logistic regression analyses serum cholesterol concentration and smoking habit were independent predictors of coronary heart disease (odds ratio serum cholesterol concentration 6.1 (95\% confidence interval $2 \cdot 1$ to $17 \cdot 6$ ), current smoking $2.9(1.1$ to $7 \cdot 5)$ ) and of all cause mortality $(3.2(1.3$ to 7.9$), 3.0(1.4$ to 6.7$)$ respectively) in diabetic men whereas systolic blood pressure, body mass index, family history, marital state, and alcohol abuse were not. Low occupational class was an independent predictor of mortality (2.4 (1.01 to 5.5)), but not of coronary heart disease, in diabetic men.

Conclusions-Middle aged diabetic men with hypercholesterolaemia are at very high risk of developing coronary heart disease and of dying prematurely. Lowering serum cholesterol concentration in such subjects seems to be warranted.

Section of Preventive Cardiology and Diabetes Section, Department of Medicine, Östra Hospital, S-416 85 Gothenburg, Sweden

Annika Rosengren, MD, senior registrar

Lennart Welin, MD, senior registrar

Alecka Tsipogianni, BSC, medical statistician

Lars Wilhelmsen, MD, head

of department of medicine

Correspondence to:

Dr Rosengren.

BrMed $f$ 1989;299:1127-31 risk factors in relation to self reported diabetes in middle aged men in whom the incidence of myocardial infarction and mortality were recorded over a mean of $7 \cdot 1$ years.

\section{Subjects and methods}

The multifactor primary prevention trial started in Gothenburg in 1970 and included all men in the city who had been born between 1915 and 1925, except those born in 1923. ${ }^{12}$ The intervention group of 10000 men comprised a random third of the men in the trial, with two control groups of 10000 men each. A first screening examination took place between January 1970 and March 1973. In the present study data were used from the second screening, which started in 1974 and was completed in 1977 . All surviving men from the intervention group who still lived in Gothenburg (9411) were invited for screening; the response rate was $76 \%$. Men who had a history of myocardial infarction (225) were excluded, leaving a population of $6897 \mathrm{men}$, aged 51-59 at baseline. Diabetes was ascertained by a postal questionnaire; all men who answered positively to the question "Did a doctor tell you that you had diabetes?" were classified as diabetics, and in a subsequent question they were asked whether they were receiving pharmacological treatment for diabetes. Blood glucose concentrations were not determined. At screening 232 men without previous myocardial infarction were classified as diabetics. Data on physical leisure activities, smoking habits, psychological stress (rated from 1 to 6, with 6 representing continuous long term stress), pharmacological treatment of hypertension, and family history of myocardial infarction were also obtained from the questionnaire.

Screening examinations were performed in the afternoon. Blood pressure was measured after five minutes' rest with the subject seated. Body mass index was calculated as weight/(height $\left.{ }^{2}\right)$. Serum cholesterol concentration (from a blood sample taken after fasting for at least two hours) was determined according to standard laboratory procedures. ${ }^{13}$

Occupational class was determined from data on occupation collected at the first screening, according to a new socioeconomic classification system (SEI) produced by the Central Bureau of Statistics in Sweden, ${ }^{14}$ is and 6000 men in the present study could be classified. Data on alcohol abuse ${ }^{16}$ and marital state were collected, with special permission, from official registers.

All men were followed up until March 1983 (mean follow up $7 \cdot 1$ years). All cases of non-fatal myocardial infarction and stroke in Gothenburg are recorded according to specific criteria. ${ }^{17}{ }^{18}$ Death certificates for men in the study were continuously collected, and the Swedish national cause specific death register was 
matched against the computer file for all men in the study. Cause specific mortality was coded according to the 8th revision of the International Classification of Diseases. Total coronary heart disease was defined as all men with either non-fatal myocardial infarction or death attributed to coronary heart disease, or both, during follow up.

The primary prevention trial was designed as an intervention study, with special measures for smokers

TABLE I-Baseline values of variables in men with and without self reported diabetes

\begin{tabular}{|c|c|c|c|}
\hline & $\begin{array}{c}\text { Without } \\
\text { diabetes } \\
(n=6665)\end{array}$ & $\begin{array}{c}\text { With } \\
\text { diabetes } \\
(\mathbf{n}=232)\end{array}$ & $\mathrm{p}$ Value \\
\hline \multirow{8}{*}{$\begin{array}{l}\text { Mean (SD) blood pressure }(\mathrm{mm} \mathrm{Hg}): \\
\text { Systolic } \\
\text { Diastolic } \\
\text { Mean (SD) heart rate (beats } / \mathrm{min}) \\
\text { Mean (SD) serum cholesterol }(\mathrm{mmol} / \mathrm{l}) \\
\text { Mean (SD) body mass index }\left(\mathrm{kg} / \mathrm{m}^{2}\right) \\
\text { No }(\%) \text { receiving treatment for } \\
\text { hypertension }\end{array}$} & $55 \cdot 3(2 \cdot 2)$ & $55 \cdot 5(2 \cdot 1)$ & 0.047 \\
\hline & & & \\
\hline & $145 \cdot 7(19 \cdot 7)$ & $154 \cdot 5(21 \cdot 2)$ & $<0.001$ \\
\hline & $92.6(11 \cdot 6)$ & $94 \cdot 5(12 \cdot 1)$ & 0.012 \\
\hline & $75 \cdot 3(12 \cdot 5)$ & $80 \cdot 5(14 \cdot 3)$ & $<0.001$ \\
\hline & $6.40(1.06)$ & $6.49(1.31)$ & 0.22 \\
\hline & $25 \cdot 6(3 \cdot 3)$ & $26 \cdot 8(4 \cdot 5)$ & $<0.001$ \\
\hline & $970(14 \cdot 6)$ & $67(28.9)$ & $<0.001$ \\
\hline $\begin{array}{l}\text { No }(\%) \text { receiving insulin or oral } \\
\text { antidiabetic agents }\end{array}$ & & $138(59 \cdot 5)$ & \\
\hline No $(\%)$ smokers & $2718(40 \cdot 8)$ & $94(40 \cdot 5)$ & $0: 89$ \\
\hline No $(\%)$ inactive during leisure time & $1039(15 \cdot 6)$ & $52(22 \cdot 4)$ & 0.0096 \\
\hline No $(\%)$ registered alcohol abusers & $452(6 \cdot 8)$ & $28(12 \cdot 1)$ & 0.0057 \\
\hline No (\%) unskilled workers* & $1334(20 \cdot 0)$ & $54(23 \cdot 3)$ & 0.091 \\
\hline No (\%) receiving disability pension & $401(6 \cdot 0)$ & $37(15 \cdot 9)$ & $<0.0001$ \\
\hline No (\%) with high stress score $†$ & $575(8 \cdot 6)$ & $35(15 \cdot 1)$ & 0.0025 \\
\hline No (\%) married & $5129(77 \cdot 0)$ & $174(75 \cdot 0)$ & 0.53 \\
\hline $\begin{array}{l}\text { No (\%) with history of coronary heart } \\
\text { disease in at least one parent }\end{array}$ & $1293(19 \cdot 4)$ & $52(22 \cdot 4)$ & 0.29 \\
\hline
\end{tabular}

^Occupational class $I$.

†Feeling of permanent stress during past five years.

TABLE II - Death and disease in men with and without diabetes during follow up

\begin{tabular}{|c|c|c|c|c|}
\hline \multirow[b]{2}{*}{ End point } & \multicolumn{2}{|c|}{ No (\%) of men: } & \multirow{2}{*}{$\begin{array}{l}\text { Odds ratio }^{\star} \\
\text { (95\% confidence } \\
\text { interval) }\end{array}$} & \multirow{2}{*}{$\begin{array}{c}\text { Odds ratio } \nmid \\
\text { (95\% confidence } \\
\text { interval) }\end{array}$} \\
\hline & $\begin{array}{l}\text { Without diabetes } \\
\quad(n=6665)\end{array}$ & $\begin{array}{l}\text { With diabetes } \\
\quad(n=232)\end{array}$ & & \\
\hline Non-fatal myocardial infarction & $216(3 \cdot 2)$ & $18(7 \cdot 8)$ & $2 \cdot 4(1.4$ to 3.9$)$ & $2 \cdot 1(1 \cdot 2$ to $3 \cdot 7)$ \\
\hline Coronary death & $150(2 \cdot 3)$ & $21(9 \cdot 1)$ & $4 \cdot 1(2 \cdot 5$ to $6 \cdot 6)$ & $3.4(1.9$ to 6.1$)$ \\
\hline Total coronary heart disease & $330(5 \cdot 0)$ & $31(13 \cdot 4)$ & $2.8(1.9$ to 4.2$)$ & $2 \cdot 3(1.4$ to 3.8$)$ \\
\hline Total (fatal and non-fatal) stroke & $72(1 \cdot 1)$ & $8(3 \cdot 4)$ & $2 \cdot 7(1.2$ to 5.9$)$ & $2 \cdot 0(0.8$ to $5 \cdot 1)$ \\
\hline Total cardiovascular deaths & $177(2 \cdot 7)$ & $27(11 \cdot 6)$ & $4.6(3.0$ to $7 \cdot 1)$ & $4 \cdot 1(2.5$ to 6.9$)$ \\
\hline \multicolumn{5}{|l|}{ Death from: } \\
\hline Cancer & $143(2 \cdot 1)$ & $8(3 \cdot 4)$ & $1.5(0.7$ to $3 \cdot 2)$ & $1.1(0.5$ to 2.9$)$ \\
\hline Other causes & $127(1.9)$ & $13(5 \cdot 6)$ & $2.9(1.6$ to $5 \cdot 3)$ & $2 \cdot 7(1.3$ to $5 \cdot 6)$ \\
\hline All causes & $447(6 \cdot 7)$ & $48(20 \cdot 7)$ & $3.5(2.5$ to 4.9$)$ & $3 \cdot 2(2 \cdot 1$ to $4 \cdot 8)$ \\
\hline
\end{tabular}

$\star$ Diabetes versus no diabetes, adjusted for age.

†Diabetes versus no diabetes, adjusted for age, serum cholesterol concentration, systolic blood pressure, smoking, body mass index, occupational class, family history, physical activity, stress score, marital state, and alcohol abuse.

TABLE III-Percentage (number) of men developing coronary heart disease or dying during follow up by quintiles of serum cholesterol concentration, systolic blood pressure, body mass index, and diabetic state

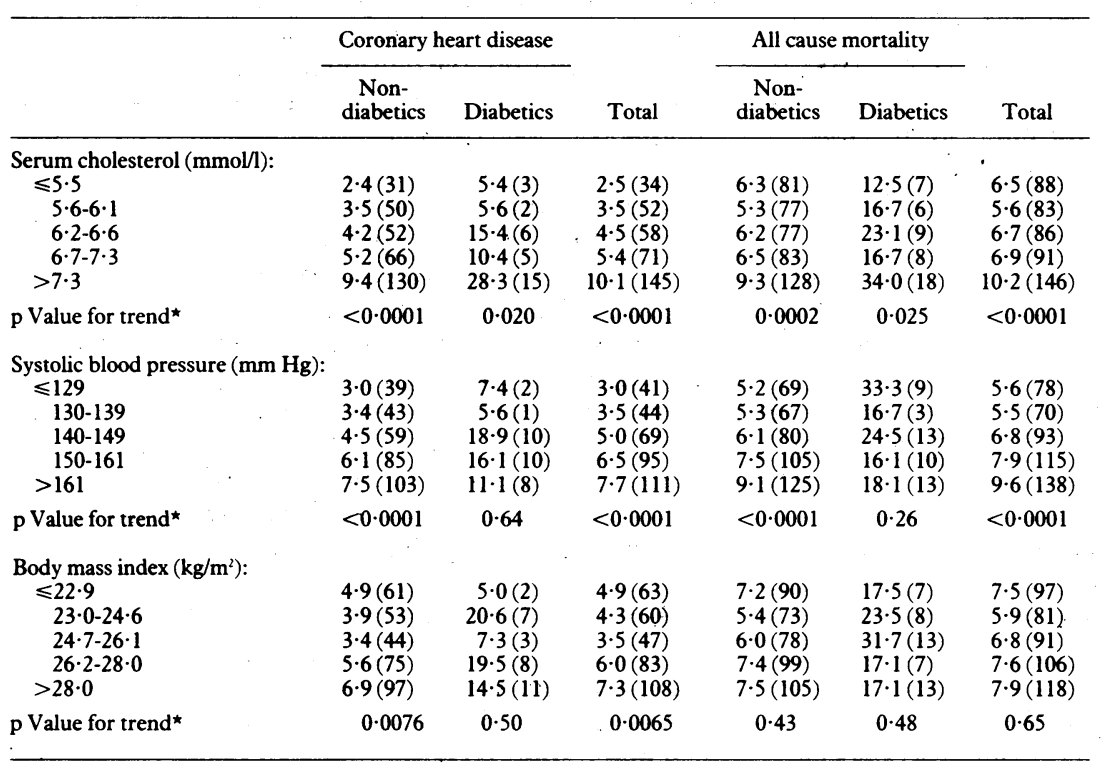

$\star$ Tested as a continuous variable. as well as for men with hypertension or hypercholesterolaemia. There were no significant differences in pattern of risk factors or outcome between the intervention group and the two equally large control groups ${ }^{12}$; consequently any changes that had occurred in the intervention group must also have taken place among the general population.

Statistical analysis-Fisher's exact test was used to test differences between two groups in a fourfold table. Possible associations between continuous variables and outcome in diabetics and non-diabetics separately were tested with logistic regression whereas a gradient test in proportions was used for graded variables. ${ }^{19}$ Adjusted odds ratios were calculated by logistic regression. ${ }^{20}$ The isotonic regression technique was used for constructing the regression surfaces.

\section{Results}

Table I shows the baseline values of variables of men in the study. Those with diabetes had significantly higher mean systolic and diastolic blood pressures, heart rates, and body mass index whereas total serum cholesterol concentration was not significantly different from that in the non-diabetics. There were no differences in smoking habits or occupational class; diabetic men, however, more commonly had disability pensions. They were more commonly physically inactive, registered for alcohol abuse, and with high stress scores than the non-diabetics.

The incidence of all:cardiovascular diseases was significantly increased among the men with diabetes (table II), but for stroke the association with diabetes no longer remained significant when other risk factors were considered. Death from causes other than cardiovascular disease or cancer were more common among men with diabetes; six of 13 deaths in this category were diagnosed as due to diabetes: three to uraemia and three to other diabetic complications. The odds ratio for all cause mortality in the diabetics compared with the non-diabetics was only slightly reduced when other factors were controlled for.

Serum cholesterol concentration was associated with the incidence of coronary heart disease as well as with all cause mortality in the diabetics and non-diabetics (table III). Diabetics with cholesterol concentrations $>7.3 \mathrm{mmol} / \mathrm{l}$ had a high rate of coronary heart disease and also high mortality. No significant association between systolic blood pressure and coronary heart disease could be detected among them; however, only three cases of coronary heart disease occurred in diabetic men with systolic blood pressure $<139$ $\mathrm{mm} \mathrm{Hg}$. As the blood pressure distribution was skewed to the right in the diabetic population, with comparatively few diabetics in the lowest two quintiles the difference was not significant. There was no association between systolic blood pressure and mortality among the diabetics, and the findings for diastolic blood pressure were similar (data not shown). Body mass index was not related to either coronary heart disease or mortality in the diabetics.

The incidence of coronary heart disease among the non-diabetic smokers was essentially double that of the non-smokers, with no increase in risk among the ex-smokers (table IV). Among the diabetics even ex-smokers had an increased risk for coronary heart disease as well as for mortality, and the rates among the smokers were substantially increased compared with the non-smokers. There were significant inverse trends for coronary heart disease and mortality in relation to occupational class among the non-diabetics. No such association could be detected for coronary heart disease among the diabetic men, but for total mortality the trend was of borderline significance $(p=0 \cdot 054)$.

Table $\mathrm{V}$ shows odds ratios adjusted by logistic 
regression for all variables in relation to fatal and nonfatal coronary heart disease and to all cause mortality for diabetics and for non-diabetics. All variables except age were dichotomised. Only serum cholesterol concentration and smoking were independently related to the incidence of coronary heart disease among the diabetics. The odds ratio for systolic blood pressure $>139 \mathrm{~mm} \mathrm{Hg}$ was $3 \cdot 7$, but the confidence interval was wide owing to the small number of cases and included unity. Serum cholesterol concentration, current smoking, and low occupational class were independent predictors of all cause mortality in diabetics. Statistical testing for a possible interaction effect between serum cholesterol concentration and diabetes for coronary heart disease and all cause mortality was nonsignificant. The odds ratio for smoking in relation to

TABLE IV-Percentage (number) of men developing coronary heart disease or dying during follow up by smoking habit, occupational class, and diabetic state

\begin{tabular}{|c|c|c|c|c|c|c|}
\hline & \multicolumn{2}{|c|}{ Coronary heart disease } & \multirow[b]{2}{*}{ Total } & \multicolumn{2}{|c|}{ All cause mortality } & \multirow[b]{2}{*}{ Total } \\
\hline & $\begin{array}{c}\text { Non- } \\
\text { diabetics }\end{array}$ & Diabetics & & $\begin{array}{c}\text { Non- } \\
\text { diabetics }\end{array}$ & Diabetics. & \\
\hline $\begin{array}{l}\text { Smoking habit: } \\
\text { Non-smoker } \\
\text { Ex-smoker } \\
\text { Current smoker }\end{array}$ & $\begin{array}{l}3 \cdot 1(58) \\
3 \cdot 4(67) \\
7 \cdot 5(203)\end{array}$ & $\begin{array}{c}5 \cdot 6(4) \\
13 \cdot 9(9) \\
19 \cdot 1(18)\end{array}$ & $\begin{array}{l}3 \cdot 2(62) \\
3 \cdot 7(76) \\
7 \cdot 9(221)\end{array}$ & $\begin{array}{l}4 \cdot 8(91) \\
4 \cdot 7(93) \\
9 \cdot 3(253)\end{array}$ & $\begin{array}{l}11 \cdot 3(8) \\
16 \cdot 9(11) \\
30 \cdot 9(29)\end{array}$ & $\begin{array}{c}5 \cdot 0(99) \\
5 \cdot 1(104) \\
10 \cdot 0(282)\end{array}$ \\
\hline $\mathrm{p}$ Value for trend & $<0.0001$ & 0.015 & $<0.0001$ & $<0.0001$ & 0.0021 & $<0.0001$ \\
\hline $\begin{array}{l}\text { Occupational class }{ }^{\star} \text { : } \\
5 \\
4 \\
3 \\
2 \\
1\end{array}$ & $\begin{array}{l}2 \cdot 7(18) \\
4 \cdot 2(45) \\
4 \cdot 8(55) \\
5 \cdot 1(81) \\
5 \cdot 8(77)\end{array}$ & $\begin{array}{c}12 \cdot 5(2) \\
12 \cdot 5(4) \\
15 \cdot 2(7) \\
4 \cdot 9(2) \\
18 \cdot 5(10)\end{array}$ & $\begin{array}{l}2 \cdot 9(20) \\
4 \cdot 4(49) \\
5 \cdot 2(62) \\
5 \cdot 1(83) \\
6 \cdot 3(87)\end{array}$ & $\begin{array}{l}3 \cdot 9(26) \\
5 \cdot 3(57) \\
6 \cdot 4(73) \\
5 \cdot 8(92) \\
8 \cdot 1(108)\end{array}$ & $\begin{array}{c}6 \cdot 3(1) \\
18 \cdot 8(6) \\
15 \cdot 2(7) \\
14 \cdot 6(6) \\
29 \cdot 6(16)\end{array}$ & $\begin{array}{l}3.9(27) \\
5.7(63) \\
6.7(80) \\
6.0(98) \\
8.9(124)\end{array}$ \\
\hline$p$ Value for trend & 0.0018 & 0.71 & 0.0017 & 0.0003 & $0 \cdot 054$ & $<0.0001$ \\
\hline
\end{tabular}

$\star^{\star}$ Class $5=$ professionals, higher civil servants, executives, and managing directors; class $4=$ intermediate non-manual employees; class $3=$ assistant non-manual employees and foremen in industrial production; class $2=$ skilled workers; employees; class $3=$ assistant non-manual employee
and class $1=$ unskilled and semiskilled workers.

TABLE v-Odds ratios* (95\% confidence intervals) for major risk factors for non-diabetics and diabetics in relation to coronary heart disease and all cause mortality

\begin{tabular}{|c|c|c|c|c|}
\hline \multirow{2}{*}{ Risk factor } & \multicolumn{2}{|c|}{ Coronary heart disease } & \multicolumn{2}{|c|}{ All cause mortality } \\
\hline & Non-diabetics & Diabetics & Non-diabetics & Diabetics \\
\hline $\begin{array}{l}\text { Serum cholesterol }(>7 \cdot 3 \text { or } \leqslant 7 \cdot 3 \mathrm{mmol} / \mathrm{l}) \\
\text { Systolic blood pressure ( }>139 \text { or }\end{array}$ & $2 \cdot 4(1 \cdot$ & $6 \cdot 1(2 \cdot 1$ & 1.7) & •9) \\
\hline$\leqslant 139 \mathrm{~mm} \mathrm{Hg}$ & $1.9(1.4$ to 2.5$)$ & $3.7(0.7$ to & $1.3(1.03$ to 1.7$)$ & $1 \cdot 1(0.4 t$ \\
\hline Current smoking (present o & $2.5(1.9$ to 3.2$)$ & $2 \cdot 9(1 \cdot 1$ & $1.9(1.5$ to 2.4$)$ & $3.0(1.4$ to 6.7$)$ \\
\hline Body mass index $\left(>28\right.$ or $\leqslant 28 \mathrm{~kg} / \mathrm{m}^{2}$ ) & $1 \cdot 6(1 \cdot 2$ to $2 \cdot 1)$ & $1.0(0.4$ & $1 \cdot 1(0 \cdot 8$ to $1 \cdot 4)$ & $0 \cdot 5(0 \cdot 2$ to $1 \cdot 3)$ \\
\hline $\begin{array}{l}\text { Family } \\
\text { (prese }\end{array}$ & 1.5( & 0 & & 0.9 \\
\hline Married or unmarried & $0.8(0.6$ to 1.2$)$ & $0.4(0.1$ to $1 \cdot 4$ & $1.3(1.01$ to 1.7$)$ & $0.9(0.3$ to $2 \cdot 5)$ \\
\hline $\begin{array}{l}\text { Low socioeconomic state (occupational } \\
\text { class } 1 / 2-5 \text { ) }\end{array}$ & $1 \cdot 2($ & & $1.3(1.03$ to 1.7$)$ & $2 \cdot 4(1 \cdot 01$ to $5 \cdot 5)$ \\
\hline Registered for alcohol abuse (yes or no) & $1.5(0.9$ to 2.3$)$ & $1.6(0 \cdot 4$ to $7 \cdot 1)$ & $2.6(1.9$ to 3.7$)$ & $0 \cdot 8(0 \cdot 2$ to $3 \cdot 3)$ \\
\hline
\end{tabular}

$\star$ Obtained by entering age and all variables in table (dichotomised and with cut off points as above) into logistic regression analyses. coronary heart disease was similar among the diabetics and non-diabetics whereas smoking seemed to confer a higher mortality risk in the diabetics than the nondiabetics; the result of a formal test for an interaction effect was, however, not significant.

The figure shows the combined effect of smoking and cholesterol concentration on the incidence of coronary heart disease in the diabetics and in the nondiabetics as depicted by the isotonic regression technique; non-smoking diabetic men with low or moderate serum cholesterol concentrations seemed to be at low risk for coronary heart disease.

\section{Discussion}

The present study confirms the well known association between coronary heart disease and diabetes and establishes hypercholesterolaemia and smoking as important risk factors within a diabetic population. Even though no significant interaction between these two factors and diabetes in relation to coronary heart disease could be shown, the combination of either with diabetes confers a substantial increase in risk.

Blood glucose concentrations were not recorded nor glucose tolerance tests performed to establish the diagnosis of diabetes in our diabetic subjects. Forty per cent of the diabetics in the study did not use insulin or oral antidiabetic agents, which is comparable to the proportion of pharmacologically untreated diabetics in other studies, ${ }^{721}$ but might indicate that some of them may have been false positives. In addition, diabetes may have been undiagnosed, ${ }^{22} 23$ and even though undiagnosed diabetes may have a milder course and less risk of complications, misclassification of diabetics into the non-diabetic group would lead to underestimation of the real differences; but the non-diabetic group was very large, and any underestimation is probably minimal.

The data collected in this survey did not permit differentiation between insulin dependent and noninsulin dependent diabetes. In another study in Gothenburg, aimed at determining the prevalence of diabetes among men aged 50 and above, however, virtually all diabetics were not dependent on insulin. ${ }^{21}$ As the present study was designed as an intervention study diabetes might have been diagnosed at a higher rate in subjects with high blood cholesterol concentrations, in the course of managing their hyperlipidaemia, than in those with normal concentrations. Even so, this might have occurred only in diabetics who were not diabetic at the first screening, and removing such subjects from the analyses made no difference to the results.

Most general population studies on diabetes in

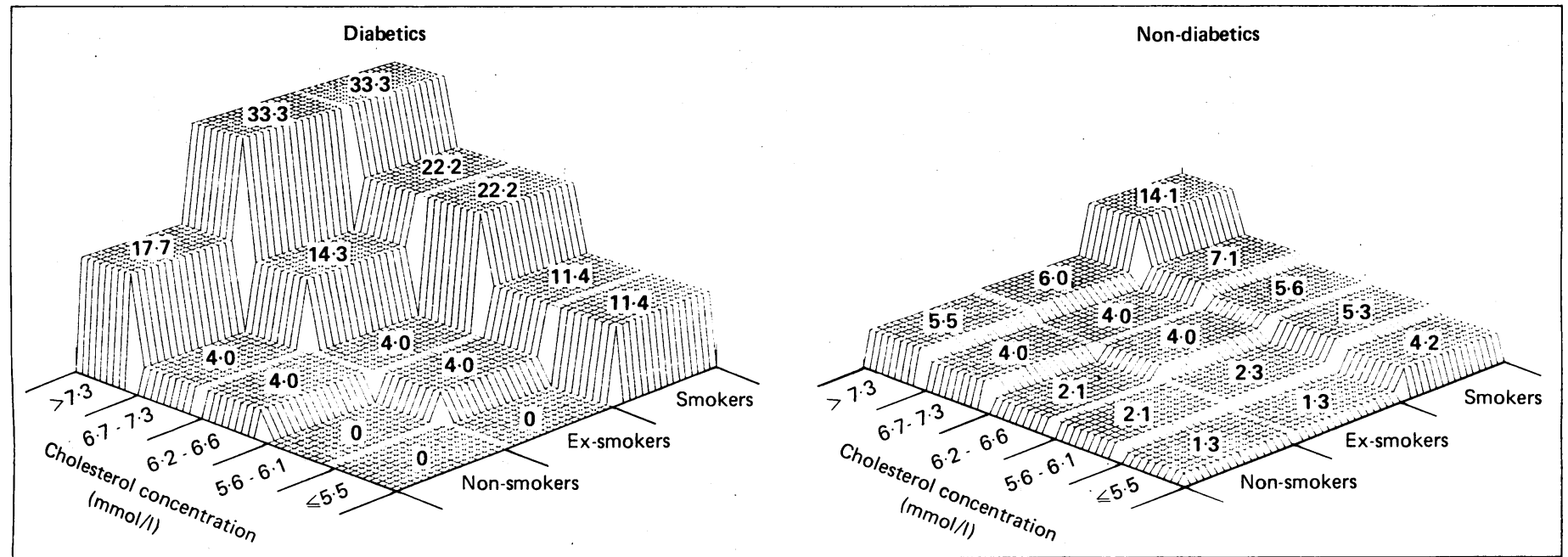

Percentage probabilities of coronary heart disease in diabetics and non-diabetics by smoking and quintiles of serum cholesterol concentration 
relation to long term sequelae have been hampered by small numbers, resulting in a lack of statistical power; this was true of the present study, but the fact that only men were studied and that their age span was fairly narrow suggests that the diabetic study population may be less heterogeneous than that of some other studies. The lack of any association between blood pressure and outcome in diabetics may, however, be due to chance. In the Whitehall study, which also examined only men, coronary heart disease mortality increased significantly with increasing systolic blood pressure ${ }^{4}$; in multiple logistic regression analyses, however, the association between hypertension and outcome in diabetics was significant only for all cause mortality and not for coronary heart disease mortality. ${ }^{24}$ In view of the well known relation between high blood pressure and obesity it is somewhat surprising that no association between coronary heart disease and this factor was found, either in the Whitehall study or in our study.

Few studies have been devoted to the combined effects of diabetes and smoking. In our study, among non-diabetics ex-smokers had virtually the same incidence of coronary heart disease and the same mortality as those who had never smoked. In contrast, diabetic ex-smokers had an increased risk. Probably diabetics were more liable to give up smoking for health reasons. Smoking seemed to double the risk for coronary heart disease and for total mortality in diabetics as well as in non-diabetics.

The role of disturbances in lipid metabolism, particularly hypercholesterolaemia, is increasingly being confirmed as causing development of atherosclerosis. Serum cholesterol concentration in the general population is now recommended to be $<5.2 \mathrm{mmol} / 1,{ }^{25}$ and diabetics are included as a risk group, demanding special attention, which seems reasonable given their very high risk of developing atherosclerotic disease. The role of hypercholesterolaemia in predicting the prognosis in diabetics, however, has not been particularly well studied. Whereas diabetics in the Framingham study contended with cardiovascular risk factors as well as nondiabetics $^{11}$ no relation between serum cholesterol concentration and coronary mortality was found in the subset of diabetics in the Whitehall study, ${ }^{4}$ which is difficult to explain. As the diabetic population was no larger than that of the present study and only coronary deaths were studied this might be due to chance variations. In our study fatal and non-fatal coronary events were similarly related to serum cholesterol concentration.

Total serum cholesterol concentration was not different between diabetic and non-diabetic men. There might, however, have been other differences in blood lipids that were not measured. Low density lipoprotein concentration, which is strongly associated with coronary heart disease, ${ }^{26}$ may be affected by diabetes. ${ }^{27}$ In contrast, high density lipoprotein concentration, which is generally regarded as protective, is decreased in diabetics. ${ }^{98}$ In addition, increased plasma concentrations of triglycerides are common in diabetes. ${ }^{928} 29$ The altered lipid metabolism in diabetes has recently been reviewed ${ }^{30}$; the complexities of the alterations may not be reflected in a single measurement of total serum cholesterol concentration; even so, this single measurement was the strongest predictor of coronary heart disease in our diabetic population. Although statistical tests for interaction between serum cholesterol concentration and diabetes with respect to coronary heart disease and mortality were non-significant, the difference in odds ratios for serum cholesterol concentration between diabetics and nondiabetics suggests that the effect of increased serum cholesterol concentration might in fact be stronger among diabetics.
Studies of populations with a low prevalence of coronary heart disease, such as that of Japan, ${ }^{31}$ have shown that this is comparatively low also among diabetics. Serum cholesterol concentrations in Sweden are high by international standards, with a concomitantly high incidence of coronary heart disease. To reduce cholesterol concentrations in the general population should be a major aim in preventive medicine; in addition, diabetic men with hypercholesterolaemia are at an extremely high risk of developing coronary heart disease. The benefits of lowering cholesterol concentration in general and selected populations have been illustrated..$^{32}$ Although pharmacological treatment reduces serum cholesterol concentration in diabetics, ${ }^{34}$ its effects on long term prognosis have yet to be investigated. Special attention to hypercholesterolaemia in diabetics in addition to vigorous antismoking counselling certainly seems to be warranted.

This study was supported by the Swedish Medical Research Council, the Swedish National Association against Heart and Chest Diseases, the Göteborg Medical Society, and the Knut and Alice Wallenberg Foundation.

1 Kannel WB, McGee DL. Diabetes and cardiovascular disease. The Framingham study. $\mathcal{F} A M A$ 1979;241:2035-8.

2 Yano K, Kagan A, McGee D, Rhoads GG. Glucose intolerance and nine-yea mortality in Japanese men in Hawaii. Am F Med 1982;72:71-80.

3 Jarrett RJ, McCartney P, Keen $\mathbf{H}$. The Bedford survey: ten year mortality rates in newly diagnosed diabetics, borderline diabetics and normoglycaemic controls and risk indices for coronary heart disease in borderline diabetics. Diabetologia 1982;22:79-84.

4 Fuller JH, Shipley MJ, Rose G, Jarrett RJ, Keen H. Mortality from coronary heart disease and stroke in relation to degree of glycaemia: the Whitehall study. BrMed F 1983;287:867-70.

5 Butler WJ, Ostrander LD, Carman WJ, Lamphiear DE. Mortality from coronary heart disease in the Tecumseh study. Long-term effect of diabetes mellitus, glucose tolerance and other risk factors. Am $\mathcal{J}$ Epidemiol 1985;121:541-7.

6 Pan WH, Cedres LB, Liu K, et al. Relationship of clinical diabetes ánd asymptomatic hyperglycemia to risk of coronary heart disease mortality in men and women. Am f Epidemiol 1986;123:504-16.

7 Kleinman JC, Donahue RP, Harris MI, Finucane FF, Madans JH, Brock DB. Mortality among diabetics in a national sample. Am $\mathcal{F}$ Epidemiol 1988;128: 389-401.

8 Jarrett RJ, Shipley MJ. Type 2 (non-insulin-dependent) diabetes mellitus and cardiovascular disease-putative association via common antecedents; further evidence from the Whitehall study. Diabetologia 1988;31:737-40.

9 Laakso M, Rönnemaa T, Pyörälä K, Kallio V, Puukka P, Penttilä I Atherosclerotic vascular disease and its risk factors in non-insulindependent diabetic and non-diabetic subjects in Finland. Diabetes Care 1988;11:449-63.

10 Kannel WB. Lipids, diabetes and coronary heart disease: insights from the Framingham study. Am Heart $\mathcal{f}$ 1985;110:1100-7.

11 Kannel WB, McGee DL. Diabetes and cardiovascular risk factors: the Framingham study. Circulation 1979;59:8-13.

12 Wilhelmsen L, Berglund G, Elmfeldt D, et al. The multifactor primary preventive trial in Göteborg, Sweden. Eur Heart $\mathcal{F}$ 1986;7:279-88.

13 Leffler HH. Estimation of cholesterol in serum. Am $\mathcal{J}$ Clin Pathol 1959;31. 310-3.

14 Statistics Sweden. Swedish socio-economic classification. Stockholm: Statistics Sweden, 1982 .

15 Rosengren A, Wedel H, Wilhelmsen L. Coronary heart disease and mortality in middle aged men from different occupational classes in Sweden. Br Med $\mathcal{F}$ 1988;297:1497-1500.

16 Rosengren A, Wilhelmsen L, Pennert K, Berglund G, Elmfeldt D. Alcoho intemperance, coronary heart disease and mortality in middle-aged Swedish men. Acta Med Scand 1987;222:201-13.

17 Elmfeldt D, Wilhelmsen L, Tibblin G, Vedin A, Wilhelmsson C, Bengtsson C. Registration of myocardial infarction in the city of Göteborg, Sweden. f Chronic Dis 1975;28:173-86.

18 Harmsen P, Berglund G, Larsson O, Tibblin G, Wilhelmsen L. Stroke registration in Göteborg, Sweden 1970-75. Acta Med Scand 1979;206: registra

19 Fleiss JL. Statistical methods for rates and proportions. New York: John Wiley, 1973:96-9.

20 Kleinbaum DG, Kupper LL, Morgenstern H. Epidemiologic research: principles and quantitative methods. Belmont, California: Lifetime Learning Publications, 1982:422-32.

21 Ohlson L-O, Larsson B, Eriksson H, Svärdsudd K, Welin L, Tibblin G. Diabetes mellitus in Swedish middle-aged men. The study of men born in 1913 and 1923. Diabetologia 1987;30:386-93.

22 Harris MI, Hadden WC, Knowler WC, Bennett PH. Prevalence of diabetes and impaired glucose tolerance and plasma glucose levels in US population aged 20-74 yr. Diabetes 1987;36:523-34.

23 Barrett-Connor $\mathbf{E}$. The prevalence of diabetes mellitus in an adult community as determined by history or fasting hyperglycemia. Am $\mathcal{J}$ Epidemiol 1980;111:705-12.

24 Jarrett RJ, Shipley MJ. Mortality and associated risk factors in diabetes. Acto Endocrinol [Suppl] (Copenh) 1985;272:21-6.

25 Study Group, European Atherosclerosis Society. Strategies for the prevention of coronary heart disease: a policy statement of the European Atherosclerosis of coronary heart disease: a policy sta

26 Kannel WB, Gordon T, Castelli WP. Role of lipids and lipoprotein fractions in assessing atherogenesis. The Framingham Study. Prog Lipid Res
1981;20:339-48. 
27 Schonfeld G, Birge C, Miller JP, Kessler G, Santiago J. Apolipoprotein B levels and altered lipoprotein composition in diabetes. Diabetes 1974;23: 827-34.

28 Uusitupa $\mathrm{M}$, Siitonen $\mathrm{O}$, Voutilainen $\mathrm{E}$, et al. Serum lipids and lipoproteins in newly diagnosed non-insulin-dependent (type II) diabetic patients with special reference to factors influencing HDL-cholesterol and triglyceride special reference to factors influe
levels. Diabetes Care 1986;9:17-22.

29 Howard BV, Knowler WC, Vasquez B, Kennedy AL, Pettitt DJ, Bennett PH. Plasma and lipoprotein cholesterol and triglyceride in the Pima Indian population. Comparison of diabetics and non-diabetics. Arteriosclerosis 1984;4:462-71.

30 Betteridge DJ. Diabetes, lipoprotein metabolism and atherosclerosis. $\mathrm{Br} \mathrm{Med}$ Bull 1989;45:285-311.

31 Keen H, Jarrett RJ. The WHO Multinational Study of Vascular Disease in $187-95$ trial with gemfbroil in middleaged men wirh dylipidemia. Safery of tral with gemfibrozil in

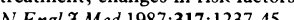

33 Blankenhorn DH, Nessim SA, Johnson RL, Sanmarco ME, Azen SP, Cashin-Hemphill L. Beneficial effects of combined colestipol-niacin therapy on coronary atherosclerosis and coronary venous bypass grafts. $J A M A$ 987;257:3233-40

34 Garg A, Grundy SM. Treatment of dyslipidemia in non-insulin-dependent diabetes mellitus with lovastatin. Am f Cardiol 1988;62:44-7.

(Accepted 14 August 1989)

\title{
Incidence of peptic ulcer disease in Gothenburg, 1985
}

\author{
Ivi-Mai Schöön, Dan Mellström, Anders Odén, Bengt-Olov Ytterberg
}

Abstract

Objective-To determine the incidence and age distribution of peptic ulcer disease in adults in Gothenburg.

Design-Retrospective study of patients with symptoms over one year.

Setting-All gastroenterology and $x$ ray departments.

Patients-Any patient found to have an active ulcer crater during 1985.

Main outcome measures-Sex, age, past history of gastrointestinal ulcers, and smoking habit.

Results-In 1985, 1402 peptic ulcers were diagnosed in 1137 adults. Over half $(403 ; 54 \%)$ of the ulcers in men and $393(60 \%)$ ulcers in women were in patients aged over 60 . All types of ulcer showed increasing incidence with age. The sex ratio of patients aged 40-50 with peptic ulcers was 1:1. Nearly half $(109 ; 48 \%)$ of ulcers diagnosed for the first time in men and $129(57 \%)$ of such ulcers in women were in patients aged over 60 . Elderly men and women were also more likely to develop haemorrhage.

Conclusions -In Gothenburg there is a surprisingly high incidence of peptic ulcer disease, which increases considerably with age, possibly explained by the availability of modern diagnostic techniques as $1121(80 \%)$ ulcers had been diagnosed by gastroscopy. Compared with earlier studies there was no difference in the incidence between men and women aged 40-50.

\section{Introduction}

During the past 20 years the death rate and rate of

Department of Surgery, Central Clinic, Östra Sjukhuset, S-416 85 Gothenburg, Sweden

Ivi-Mai Schöön, MD, registrar

Clinic V, Vasa Hospital, Gothenburg

Dan Mellström, MD, senior consultant

Bengt-Olov Ytterberg, MD, registrar

\section{Department of}

Mathematics, University of Gothenburg, Gothenburg

Anders Odén, PHD, associate professor

Correspondence to:

Dr Schöön.

BrMed f 1989;299:1131-4 $a l^{13}$ used gastroscopic findings; other investigations are based on $x$ ray diagnosis or inpatient series, or both. In Sweden gastroscopy is the primary means of investigating suspected peptic ulcer, and in $1985,80 \%$ (1121) of all diagnoses of ulcers made in Gothenburg were confirmed by gastroscopy. We investigated the incidence of peptic ulcer disease during a period when decreasing mortality, surgical intervention, and hospital admissions for this condition were reported.

\section{Patients and methods}

The figure of 360042 for the adult population of Gothenburg - that is, people aged over 15-was estimated as the mean of the numbers registered on 31 December 1984 and 31 December 1985. The figures were derived from the local population register of all residents in one year age classes. The population was divided into age groups of five or 10 years for calculation of the age specific incidence. In Gothenburg $1 \cdot 2 \%$ of people aged over 65 and $14 \%$ of men aged 40 are immigrants, most having come from Finland, usually at the age of about 20 . In Sweden all residents belong to the social insurance system, which means that the consumption of medical care is uniformly distributed. Endoscopic methods are therefore widely used in both inpatients and outpatients.

Peptic ulcers diagnosed during 1985 were registered in collaboration with all gastroenterology departments performing gastroscopies and all $x$ ray departments. In 1985 gastroscopy was performed at three major surgical centres, one major department of internal medicine, two smaller hospital departments, and three private practices. Data about all gastroscopies performed in Gothenburg were recorded during the year.

The $x$ ray units equipped with organ specific computerised registers supplied results of all barium meals. Of the 1137 patients with active ulcer craters, 1013 were interviewed by telephone about earlier episodes of ulcers, other relevant disease, and smoking habits. The relations between smoking habits among the population as a whole and the patients with peptic ulcer of the present study will be presented in a separate paper.

Hospital records of patients with perforated or bleeding ulcers diagnosed at an emergency operation without previous gastroscopy were collected during the year from the two hospitals with casualty departments. Patients found to have no ulcer crater at the time of operation were excluded. Gastric ulcers were defined as ulcers near to or proximal to the gastric angulus; prepyloric ulcers as ulcers on the gastric side of the pylorus or within $3 \mathrm{~cm}$ proximal to the pylorus; and duodenal ulcers as ulcers located in the duodenal bulb or on the distal part of the pyloric valve. 